Subscriber access provided by University of East Anglia Library

Energy and Climate

\title{
CO2 Emissions Embodied in International Migration from 1995 to 2015
}

Sai Liang, Xuechun Yang, Jianchuan Qi, Yutao Wang, Wei Xie, Raya Muttarak, and Dabo Guan

Environ. Sci. Technol., Just Accepted Manuscript • DOI: 10.1021/acs.est.0c04600 • Publication Date (Web): 31 Aug 2020

Downloaded from pubs.acs.org on September 6, 2020

\section{Just Accepted}

"Just Accepted" manuscripts have been peer-reviewed and accepted for publication. They are posted online prior to technical editing, formatting for publication and author proofing. The American Chemical Society provides "Just Accepted" as a service to the research community to expedite the dissemination of scientific material as soon as possible after acceptance. "Just Accepted" manuscripts appear in full in PDF format accompanied by an HTML abstract. "Just Accepted" manuscripts have been fully peer reviewed, but should not be considered the official version of record. They are citable by the Digital Object Identifier (DOI@). "Just Accepted" is an optional service offered to authors. Therefore, the "Just Accepted" Web site may not include all articles that will be published in the journal. After a manuscript is technically edited and formatted, it will be removed from the "Just Accepted" Web site and published as an ASAP article. Note that technical editing may introduce minor changes to the manuscript text and/or graphics which could affect content, and all legal disclaimers and ethical guidelines that apply to the journal pertain. ACS cannot be held responsible for errors or consequences arising from the use of information contained in these "Just Accepted" manuscripts. 
$1 \mathrm{CO}_{2}$ Emissions Embodied in International Migration from 1995 to 2015

2 Sai Liang ${ }^{\dagger}+$, Xuechun Yang ${ }^{\ddagger}$, Jianchuan Qi ${ }^{\dagger} \ddagger$, Yutao Wang *, $\S$, Wei Xie ${ }^{\S}$,

3 Raya Muttarak $\|, \perp$, Dabo Guan *, ๆ

$4 \dagger$ Key Laboratory for City Cluster Environmental Safety and Green Development of

5 the Ministry of Education, Institute of Environmental and Ecological Engineering,

6 Guangdong University of Technology, Guangzhou, Guangdong, 510006, China.

$7 \$$ State Key Joint Laboratory of Environment Simulation and Pollution Control,

8 School of Environment, Beijing Normal University, Beijing, 100875, China.

$9 \S$ Fudan Tyndall Center and Shanghai Key Laboratory of Atmospheric Particle

10 Pollution and Prevention (LAP3), Department of Environmental Science \&

11 Engineering, Fudan University, Shanghai, 200438, China.

$12 \|$ Wittgenstein Centre for Demography and Global Human Capital, International

13 Institute for Applied Systems Analysis, Laxenburg, A2361, Austria.

$14 \perp$ School of International Development, University of East Anglia, Norwich, NR4

$157 \mathrm{TJ}, \mathrm{UK}$.

16 I Department of Earth System Science, Tsinghua University, Beijing, 100080, China.

17

18 * Corresponding author: yutaowang@,fudan.edu.cn (Yutao Wang);

19 guandabo@hotmail.com (Dabo Guan). 


\section{ABSTRACT}

22 Whilst present international $\mathrm{CO}_{2}$ mitigation agreements account for the impact of

23 population composition and structure on emissions, the impact of international

24 migration is overlooked. This study quantifies the $\mathrm{CO}_{2}$ footprint of international

25 immigrants and reveals their non-negligible impacts on global $\mathrm{CO}_{2}$ emissions. Results

26 show that the $\mathrm{CO}_{2}$ footprint of international immigrants has increased from 1.8

27 Gigatonnes (Gt) in 1995 to 2.9 Gt in 2015. In 2015, the U.S. had the largest total and

28 per capita $\mathrm{CO}_{2}$ emissions caused by international immigrants. Oceania and the Middle

29 East are highlighted for their large portions of immigrant-caused $\mathrm{CO}_{2}$ emissions in

30 total $\mathrm{CO}_{2}$ emissions (around 20\%). Changes in the population and structure of global

31 migration have kept increasing global $\mathrm{CO}_{2}$ emissions during 1995-2015, while the

32 reduction of $\mathrm{CO}_{2}$ emission intensity helped offset global $\mathrm{CO}_{2}$ emissions. The global

$33 \mathrm{CO}_{2}$ mitigation targets must consider the effects of global migration and demand-side

34 measures need to concern major immigrant influx nations.

35 Keywords: international migration, immigrant, climate change, $\mathrm{CO}_{2}$ emissions, trade,

36 consumption.

37 Synopsis: This study links the population mobility with global $\mathrm{CO}_{2}$ mitigation, which

38 evaluates the contribution of international immigrants to global $\mathrm{CO}_{2}$ emissions. 


\section{INTRODUCTION}

42 International migration is a phenomenon accompanying the process of human

43 civilization and globalization. In recent decades, the number of international

44 immigrants has proliferated and the destinations of immigrants have become

45 increasingly diversified. International migration has a variety of implications on the

46 place of destination including politics, economy, culture and welfare security issues. ${ }^{1-}$

$47 \quad 3$

48 Migration can be a critical demographic factor affecting the environment. ${ }^{4}$ Previous

49 studies have investigated the environmental impacts of regional migration (including

50 interregional migration, rural-rural migration, and rural-urban migration) on land

51 use, ${ }^{5,6}$ forest cover, ${ }^{7,8}$ air pollutant emissions, ${ }^{9,} 10$ and carbon emissions. ${ }^{11-13}$

52 Population migration has implications for carbon emissions mainly because migration

53 flows affect population size and structure both at the origin and destination. Not only

54 does migration-induced population growth translates into higher energy consumption,

55 migration process can bring about lifestyle change which influences consumption

56 pattern and consequently $\mathrm{CO}_{2}$ emissions ${ }^{14}$. This line of argument has been put

57 forward to campaign for restriction of immigration for example in the US because

58 population growth induced by migration coupled with the American lifestyle adopted by immigrants will have consequential environmental impact ${ }^{15,16}$. 
60 The evidence on the impact of migration on the environment however is inconclusive.

61 On the one hand, rural to urban migration within a country is typically found to be

62 associated with an increase in $\mathrm{CO}_{2}$ emissions given a rise in the demand for

63 residential energy in the urban area and lifestyle change thanks to increased income

64 level ${ }^{13,17}$. On the other hand, studies on the environmental impact of immigration

65 measured by air quality and air pollutant emissions focusing on the US do not find

66 evidence that immigration contribute to heightened air pollution levels ${ }^{18,19}$. Ma and

67 Hofmann even find that the presence of immigrant population is associated with better

68 overall air quality ${ }^{20}$ possibly because migrants express greater environmental

69 concerns and have lower energy consumption than the US native born. The

70 inconclusive nature of the evidence calls for further research using different indicators

71 of environmental impact ${ }^{20}$ as well as cross-national comparisons between sending

72 countries with high and low emissions ${ }^{18}$.

73 Indeed, more accurate and objective studies about the migration-environment

74 relationship are needed since they have relevant policy implications. However, little

75 attention is paid to the impacts of international migration on environmental emissions

76 at the global scale. In the context of enormous challenges of global climate change,

77 the international community formulates active $\mathrm{CO}_{2}$ mitigation agreements to keep the

78 temperature arisen within 2 degrees at the end of this century. However, these

79 agreements do not account for changing population structure and distribution which

80 can shift the global patterns of $\mathrm{CO}_{2}$ emissions. A study of population mobility finds a 
81 significant contribution of tourism on global $\mathrm{CO}_{2}$ emission growth, especially in the

82 sectors such as transportation, food, and accommodations. ${ }^{21}$ If a short-term population

83 movement like tourism has a substantial impact on $\mathrm{CO}_{2}$ emissions, this raises an

84 important question how migration as a long-term population movement will impact

85 the global emissions. ${ }^{22-24}$. Longer term population mobility involves comprehensive

86 consumption sectors (e.g., housing, infrastructure, energy use, health care, and

87 education) which would lead to long-term environmental impacts. Given the current

88 trends that international migration will continue to play a role in global population

89 dynamics coupled with the intensity of globalization and labor transfer, global $\mathrm{CO}_{2}$

90 emissions caused by international migration are no doubt worthy of critical attention.

91 However, the impacts of international migration on global $\mathrm{CO}_{2}$ emissions are not well

92 evaluated.

93 To that end, this study fulfills the above knowledge gap by analzing the impacts of

94 international migration on global $\mathrm{CO}_{2}$ emissions. We construct a set of international

95 migration matrixes to uncover the sources, destinations, and quantities of the migrant

96 population. Then we evaluate the $\mathrm{CO}_{2}$ footprint of the international immigrants and

97 the impacts of international migration on global $\mathrm{CO}_{2}$ emissions. Findings of this study

98 can contribute to the formulation of $\mathrm{CO}_{2}$ mitigation strategies in different nations with

99 the consideration of future immigrants. 


\section{MATERIALS AND METHODS}

102

103

104

105

106

107

108

109

110

111

112

113

114

115

116

117

118

\section{Constructing International Migration Matrixes. This study constructs the} migration matrixes in $1995,2000,2005,2010$, and 2015 to describe the international migrant stock by destination and origin. Each row of the matrixes represents emigrants from a country of origin, while each column denotes the immigrants to a country of destination. Thus, the sum of each row equals the original population of a nation, while the sum of each column equals the current population of a nation. The diagonal elements of the matrixes represent the population which do not emigrate. The migration matrixes are constructed with the international migration data and national population data. The international migration data are from the dataset of the United Nations Department of Economic and Social Affairs (UN DESA) ${ }^{25}$. This dataset presents the estimates of international immigrants by ages, sexes, and origins, based on official statistics on the foreign-born or foreign population. The national population data are from the World Bank ${ }^{26}$.

$\mathrm{CO}_{2}$ Footprint of Immigrants. We use a global environmentally extended multiregional input-output (EE-MRIO) model to evaluate the $\mathrm{CO}_{2}$ footprint of nations and their immigrants. The EE-MRIO model has been widely used to investigate environmental issues related to socioeconomic activities, such as $\mathrm{CO}_{2}$ emissions, ${ }^{27-29}$ mercury emissions, ${ }^{30,31}$ resource extraction and scarcity, ${ }^{32-34}$ and health risks ${ }^{35,36}$. We construct a global EE-MRIO model by treating global $\mathrm{CO}_{2}$ emissions as the satellite account of the global MRIO table. We use the global MRIO tables from the Eora 
122 database ${ }^{37,38}$, mainly due to two reasons: (1) Eora covers 190 nations/regions, which

123 is more than other global MRIO databases. Thus, it is suitable for investigating the

124 issue of international migration. (2) Eora has a complete time series for 1990-2015,

125 which covers all the time points in this study. ${ }^{37,38}$ This study groups all the nations

126 into 13 sub-regions considering geographical factors and their significance for

127 migration, including the U.S., Canada, Mexico, China, India, South America,

128 European Union (EU), Russia and CIS (Commonwealth of Independent States)

129 regions, Southeast Asia, Middle East, Africa, Oceania, and the Rest of the World

130 (RoW). The list of nations and corresponding sub-regions are shown in SI Data S4.

131 Data for the satellite account of global $\mathrm{CO}_{2}$ emissions are also from the Eora database.

132 We use the satellite account of $\mathrm{CO}_{2}$ emissions generated from the PRIMAP-HIST

133 dataset, as recommended by the Eora database. The selected satellite account is the

134 National Total (CAT0) $\mathrm{CO}_{2}$ emissions. It covers all the sources of $\mathrm{CO}_{2}$ emissions,

135 including the Total Energy, Industrial Processes, Land Use, Land Use Change, and

136 Forestry (LULUCF), etc.

137 The $\mathrm{CO}_{2}$ footprints of nations are calculated by the Leontief MRIO model, as shown

138 in equation (1).

$139 c f_{n}=q(\mathbf{I}-\mathrm{A})^{-1} y_{n}$

140 The notation $c f_{n}$ represents the $\mathrm{CO}_{2}$ footprint of nation $n$. The row vector $q$ indicates

141 the $\mathrm{CO}_{2}$ emission intensity, where each element $q_{i}$ represents the $\mathrm{CO}_{2}$ emissions for

142 unitary output of nation sector $i$. The matrix $\mathbf{A}$ is the direct input coefficient matrix, 
143 where the element $a_{i j}$ equals to the direct input from nation sector $i$ to nation sector $j$

144 divided by the total output of nation sector $j$. The matrix I is an identify matrix. The

145 matrix $(\mathbf{I}-\mathbf{A})^{-1}$ is the Leontief Inverse matrix, where the element $l_{i j}$ indicates

146 both direct and indirect inputs from nation sector $i$ to satisfy unitary final demand of

147 sector $j$. The vector $y_{n}$ represents the final demand of nation $n$.

148 The $\mathrm{CO}_{2}$ footprint of immigrants in a nation is calculated with the $\mathrm{CO}_{2}$ footprint of

149 this nation and the proportion of immigrants in the current population of this nation,

150 as shown in equation (2).

151

$$
c f_{m, n}^{i m m i}=c f_{n} \times \frac{p_{m, n}^{i m m i}}{p_{n}^{\text {total }}}
$$

152 The notation $c f_{m, n}^{i m m i}$ indicates the $\mathrm{CO}_{2}$ footprint in nation $n$ caused by the immigrants

153 from nation $m(m \neq n)$. The notation $p_{m, n}^{i m m i}$ represents the population of immigrants

154 from nation $m$ to nation $n$, and the notation $p_{n}^{\text {total }}$ denotes the total current population

155 of nation $n$. Consequently, the $\mathrm{CO}_{2}$ footprint of immigrants to nation $n\left(c f_{n}^{i m m i}\right)$ and

156 that of the world ( $\left.c f^{i m m i}\right)$ are calculated by equations (3) and (4), respectively.

$157 \quad c f_{n}^{i m m i}=\sum_{m} c f_{m, n}^{i m m i}$

158

$c f^{i m m i}=\sum_{n} c f_{n}^{i m m i}$

159 Structural Decomposition Analysis. We combine the structural decomposition analysis (SDA) with the EE-MRIO model to investigate the relative contribution of

161 the international migration to global $\mathrm{CO}_{2}$ emissions during 1995-2015. In this study, we decompose global $\mathrm{CO}_{2}$ emission changes into the relative contributions of the 
163 changes in $\mathrm{CO}_{2}$ emission intensity, production structure, final demand structure, per

164 capita final demand level of the current population, migration structure, and original

165 population.

166 Global $\mathrm{CO}_{2}$ emissions can be expressed with the global EE-MRIO model, as shown in 167 equation (5)

$168 t=q \times(\mathbf{I}-\mathrm{A})^{-1} \times y$

169 The notation $t$ denotes global $\mathrm{CO}_{2}$ emissions, and $q$ is a vector of $\mathrm{CO}_{2}$ emission

170 intensity of nation sectors. The matrix $(\mathbf{I}-\mathbf{A})^{-1}$ is the Leontief Inverse matrix, and

$171 y$ is a vector of the final demand.

172 The final demand vector $y$ can be further decomposed into the final demand structure,

173 per capita final demand level, and population, as shown in equation (6).

$174 y=y_{s} \times \hat{y_{v}} \times p$

175 The notation $y_{s}$ represents the final demand structure, which is the proportion of the

176 nation sectors in the total final demand. The notation $y_{v}$ denotes the per capita final

177 demand level, and $p$ represents the current population of nations. The hat notation ${ }^{\wedge}$

178 denotes the diagonalization of a vector.

179 To investigate the relative contribution of the international migration, we further

180 decompose the population into vector $e$, migration structure matrix $\mathbf{B}$, and original

181 population $m$, as shown in equation (7).

$p=(e \times \hat{m} \times \mathbf{B})^{T}$ 
183 The elements of the row vector $e$ are all 1 . The notation $m$ represents a vector of the

184 original population of nations. The matrix $\mathbf{B}$ indicates the migration structure, where

185 the element $b_{i j}$ equals to the number of immigrants from nation $i$ to nation $j$ divided

186 by the original population of nation $i$. The hat notation ${ }^{\wedge}$ and the notation $T$ denote the

187 diagonalization and transposition of a vector, respectively. Consequently, global $\mathrm{CO}_{2}$

188 emissions can be expressed by equation (8).

189

$t=q \times(\mathbf{I}-\mathbf{A})^{-1} \times y_{s} \times \hat{y_{v}} \times \mathbf{B}^{T} \times \hat{m}^{T} \times e^{T}$

190 We use $\mathbf{L}$ to represent the Leontief Inverse matrix $(\mathbf{I}-\mathrm{A})^{-1}$. The changes in global

$191 \mathrm{CO}_{2}$ emissions can be expressed by equation (9). Items in the right-hand side of

192 equation (9) represent the relative contributions of the changes in $\mathrm{CO}_{2}$ emission

193 intensity $\Delta q$, production structure $\Delta \boldsymbol{L}$, final demand structure $\Delta y_{s}$, per capita final

194 demand level of the current population $\Delta \hat{y_{v}}$, migration structure $\Delta \boldsymbol{B}^{T}$, and the

195 original population $\Delta \hat{m}^{T}$ to global $\mathrm{CO}_{2}$ emission changes $\Delta t$.

196

$\Delta t=\Delta q \times \boldsymbol{L} \times y_{s} \times \hat{y_{v}} \times \mathbf{B}^{T} \times \hat{m}^{T} \times e^{T}$

197

$$
+q \times \Delta \boldsymbol{L} \times y_{s} \times \hat{y_{v}} \times \mathbf{B}^{T} \times \hat{m}^{T} \times e^{T}
$$

198

$$
+q \times \boldsymbol{L} \times \Delta y_{s} \times \hat{y_{v}} \times \mathbf{B}^{T} \times \hat{m}^{T} \times e^{T}
$$

$$
+q \times \boldsymbol{L} \times y_{s} \times \Delta \hat{y_{v}} \times \mathbf{B}^{T} \times \hat{m}^{T} \times e^{T}
$$

200

$$
+q \times \boldsymbol{L} \times y_{s} \times \hat{y_{v}} \times \Delta \boldsymbol{B}^{T} \times \hat{m}^{T} \times e^{T}
$$

$$
+q \times \boldsymbol{L} \times y_{s} \times \hat{y_{v}} \times \boldsymbol{B}^{T} \times \Delta \hat{m}^{T} \times e^{T}
$$


202 We have 6 decomposition forms, and we average all the 6 decompositions to calculate

203 the relative contributions of the decomposed factors. Moreover, to make the indicators

204 in different time points comparable, we convert the current-price global MRIO tables

205 (in U.S. dollars) to ones in 1995 constant prices (in U.S. dollars) using methods of

206 previous studies ${ }^{39,40}$. Such a conversion can eliminate the effects of price changes

207 caused by inflation or deflation. Producer Price Index (PPI) is an economic index

208 reflecting the price changes during a time period. It is typically used to convert

209 comparable prices. The PPIs used for the conversion in this study are from the United

210 States Bureau of Labor Statistics ${ }^{41}$.

212 RESULTS

213 International Migration During 1995-2015. The number of international

214 immigrants are 161 million (2.8\% of the total global population) in 1995. This

215 percentage has shown an upward trend from 1995 to 2015 with slight fluctuations.

216 International immigrants reach 248 million (3.4\% of the total global population) in

217 2015. The quantity of international immigrants has increased by $54 \%$ during $1995-$

2182015 (more results in SI Data S1).

219 Figure 1a shows that, in 2015, the most significant international migration corridors

220 are from Mexico to the U.S., from Africa to the European Union (EU), and from India

221 to the Middle East. The migration corridors highlighted in Figure 1a can be generally 
222 classified into three types: from developing regions to developed nations (e.g., from

223 Mexico to the U.S., from South America to EU countries,), labour exports (e.g., from

224 India and Southeast Asia to the Middle East, and from Southeast Asia to the U.S.),

225 and refugee flows (e.g., from Africa and Middle East to the EU). The U.S. is a

226 primary destination for migrants from Mexico, India, and China (including Chinese

227 Mainland, Hongkong, Macao, and Taiwan). The number of immigrants in the U.S.

228 exceed 320 million in 2015 (SI Figure S1).

229 Figure $1 \mathrm{~b}$ shows the changes in the migration population from 1995 to 2015.

230 Migration to the U.S. expanded the most. During 1995-2015, immigrants from

231 Mexico, Southeast Asia, South America, India, and China to the U.S. increased

232 dramatically. Meanwhile, immigrants from India to the Middle East presented the

233 most substantial increments. In contrast, the migrant population in Russia, Ukraine,

234 and India decreased remarkably. In Asia, the number of migrants from India in United

235 Arab Emirates (labour exports) increased substantially, while the number of migrants

236 from Iraq in Iran decreased (SI Figure S1). 

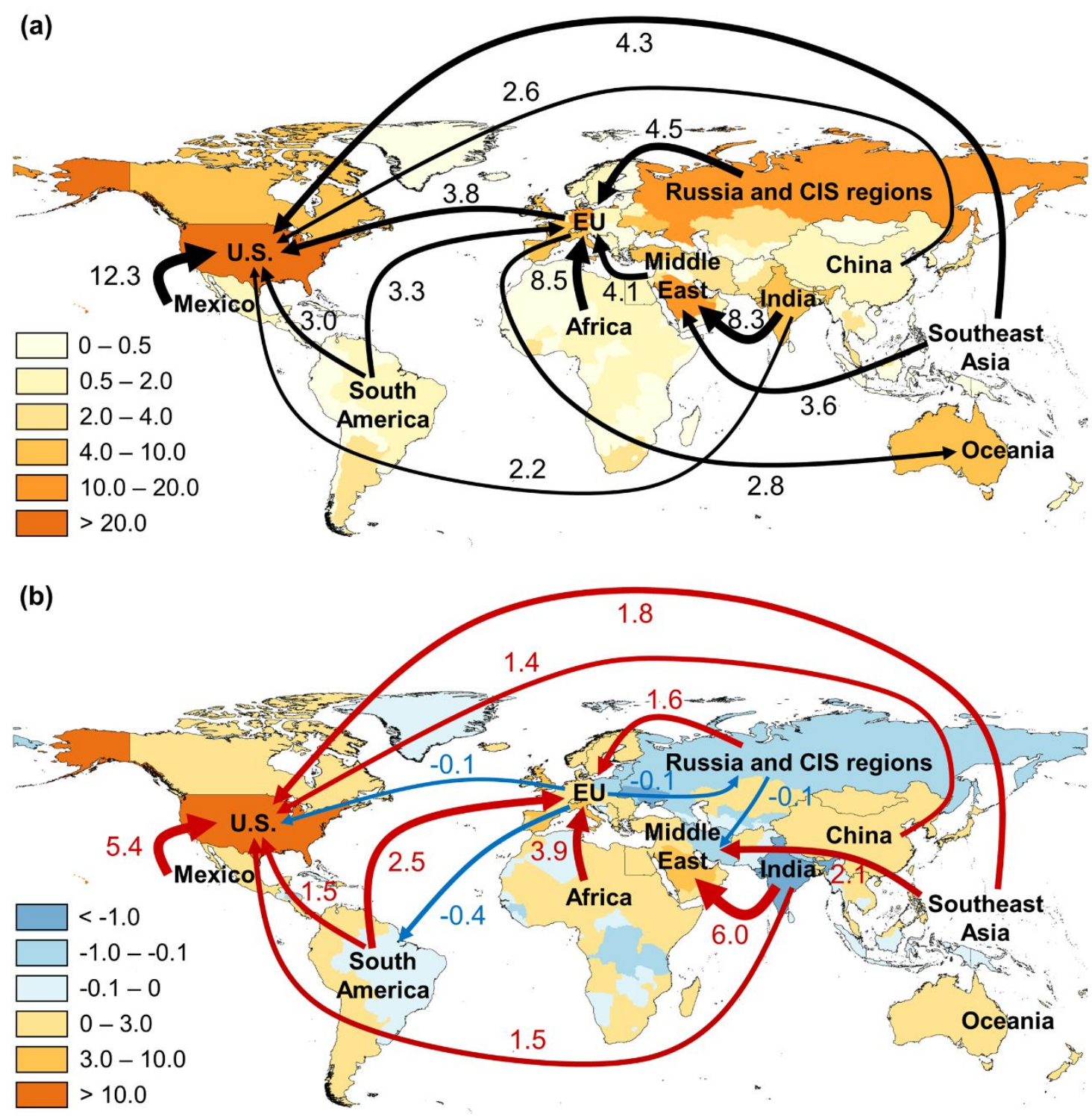

238 Figure 1. Global migration population in 2015 and migration changes during 1995-

239 2015. Panel (a) shows global migration in 2015 (million), and panel (b) shows

240 changes in the number of global migration during 1995-2015 (million). The colour of

241 nations in the world maps shows the number of migrant population (a) and changes in

242 migrant population (b). The arrows start from the origins of immigrants and end at

243 their destinations (at the sub-regional scale). The red arrows indicate an increased

244 population of immigrants, while the blue ones represent a decrease. The numbers and 
245 width of the arrows indicate the migrant population (a) and the migrant population

246 changes (b).

$247 \mathrm{CO}_{2}$ Footprint of International Immigrants. The $\mathrm{CO}_{2}$ footprint of international

248 immigrants is 1.8 Gigatonnes $(\mathrm{Gt})$, occupying $6 \%$ of the global total $\mathrm{CO}_{2}$ emissions in

249 1995. It has shown an upward trend during 1995-2015 with slight fluctuations, and

250 reaches $2.9 \mathrm{Gt}(8 \%)$ in 2015 . The $\mathrm{CO}_{2}$ footprint of international immigrants has

251 increased by 65\% during 1995-2015 (more results in SI Data S2).

252 Figure 2a shows global $\mathrm{CO}_{2}$ emissions caused by international migration (hereinafter

253 called immiCO , which is part of the $\mathrm{CO}_{2}$ footprint of the migrants receiving nation)

254 in 2015. The developing regions are generally net exporter of $\mathrm{immiCO}_{2}$, while the

255 developed regions mostly act as net importers of immiCO2.

256 The U.S. has the highest immiCO $_{2}$ in 2015 (947 million ton, Mt). The immigrants

257 from Mexico contribute the most (25\% of the $\mathrm{immiCO}_{2}$ in the U.S.), followed by

258 Southeast Asia (9\%), the EU (8\%), and South America (6\%). The $\mathrm{immiCO}_{2}$ flows are

259 in consistent with typical migration corridors such as corridors from developing

260 regions to developed regions and labour export corridors. For instance, Mexico, a

261 developing economy, has been one of the largest origins of immigrant population in

262 the U.S. The immigrants from Mexico move to the U.S. for job opportunities and

263 better living conditions (e.g., better healthcare and education). The improvement of

264 personal income and living conditions promote the consumption of immigrants. This 
265 can drive larger $\mathrm{CO}_{2}$ emissions from the upstream regions/sectors in the supply

266 chains, and hence increases $\mathrm{CO}_{2}$ footprint of the U.S. The U.S. is the primary

267 migration destination with a diverse migrant composition, which leads to enormous

268 effects of the immigrants on global $\mathrm{CO}_{2}$ emissions.

269 The $\mathrm{immiCO}_{2}$ of the Middle East (513 Mt) rank second, mainly induced by

270 immigrants from India (leading to $38 \%$ of the $\mathrm{immiCO}_{2}$ in the Middle East) and

271 Southeast Asia (13\%). In particular, immigrants from India to the United Arab

272 Emirates and Qatar are the most critical causes of $\mathrm{immiCO}_{2}$ in the Middle East (SI

273 Figure S2). The United Arab Emirates and Qatar have small populations, with

274 immigrant populations accounting for the majority (SI Data S1). Their prosperous

275 economic development requires large amounts of labour forces. These nations attract

276 overseas labour forces, especially immigrants from India. This reveals that labour

277 export to the Middle East results in large amounts of global $\mathrm{CO}_{2}$ emissions. For the

$278 \mathrm{EU}$, the $\mathrm{immiCO}_{2}$ reaches $274 \mathrm{Mt}$, with Africa, South America, and Russia and CIS

279 (Commonwealth of Independent States) contributing significantly. The refugee flows

280 from Africa to EU lead to large amounts of $\mathrm{immiCO}_{2}$. The political unrest and severe

281 natural disaster in Africa bring about lots of refugees, and EU becomes the main

282 destination of African refugees. $\mathrm{CO}_{2}$ emissions driven by immigrant refugees cannot

283 be neglected.

284 From 1995 to 2015, the migration flows from India to the Middle East lead to the

285 most massive global $\mathrm{CO}_{2}$ emissions (Figure $2 \mathrm{~b}$ ). Notably, the $\mathrm{immiCO}_{2}$ flows from 
India to Qatar and the United Arab Emirates significantly increased $\mathrm{immiCO}_{2}$ of the

287 Middle East (SI Figure S2). The immiCO $_{2}$ of the U.S. has increased and then declined 288 slightly during 1995-2015, while its portion in total $\mathrm{CO}_{2}$ emissions of the U.S.

289 steadily has increased from $11 \%$ in 1995 to $15 \%$ in 2015 (more results in SI Data S3).

290 Figure $2 \mathrm{~b}$ also shows that all the $\mathrm{immiCO}_{2}$ flows from Mexico, Southeast Asia, India,

291 China, South America, and Africa to the U.S. have increased. This finding is in

292 accordance with the changes in migration trends. On the other hand, $\mathrm{immiCO}_{2}$ flows

293 from the EU to the U.S., South America, and Russia and CIS have shown a small

294 decrease.

295 In 2015, the per capita $\mathrm{immiCO}_{2}$ of the U.S. reached 20 ton/capita, followed by

296 Oceania (12 ton/capita) and the EU (8 ton/capita). Although the U.S. and the EU are

297 both major destinations of immigrants, they are evidently different in terms of per

298 capita $\mathrm{immiCO}_{2}$. The value of the U.S. is approximately 2.5 times as that of the EU

299 (Figure 2c). In Africa and India, the per capita $\mathrm{immiCO}_{2}$ is the lowest. At the national

300 level, nations with the highest per capita $\mathrm{immiCO}_{2}$ include Qatar (48 ton/capita) and

301 San Marino (41 ton/capita), which have small populations. Moreover, the $\mathrm{immiCO}_{2}$ in

302 Luxembourg, United Arab Emirates, and Singapore all exceeded 30 ton/capita (SI

303 Figure S2).

304 Oceania and the Middle East are highlighted for their large portions of $\mathrm{immiCO}_{2}$ in

305 their total $\mathrm{CO}_{2}$ emissions, with the percentages of $22 \%$ and $20 \%$, respectively. The

$306 \mathrm{immiCO}_{2}$ in the U.S. and EU, which are major migration destinations, account for 
$307 \quad 15 \%$ and $7 \%$ of their total $\mathrm{CO}_{2}$ emissions, respectively (Figure $2 \mathrm{~d}$ ). At the national 308 level, the percentages in the United Arab Emirates, Kuwait, and Qatar all exceeded $30965 \%$, which were the highest in 2015 (SI Figure S2). $\mathrm{CO}_{2}$ emissions of the

310 emphasized areas are more greatly influenced by international migration. Prospect

$311 \mathrm{CO}_{2}$ reduction strategies in these areas are suggested to take the quantity and structure 312 of population movement into account. 
(a)

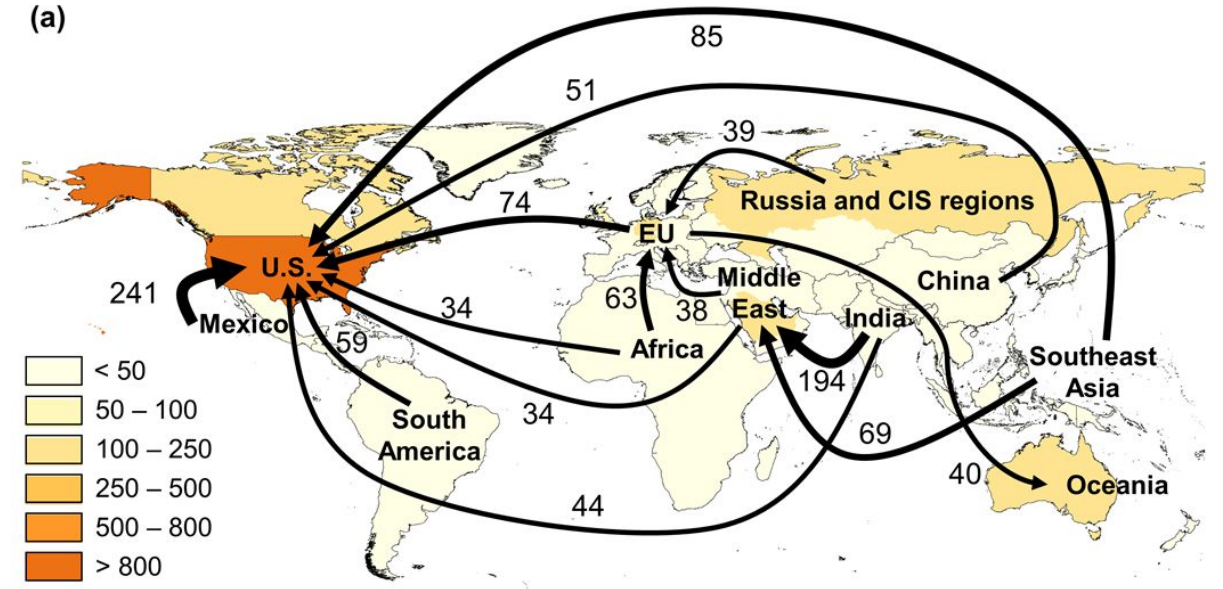

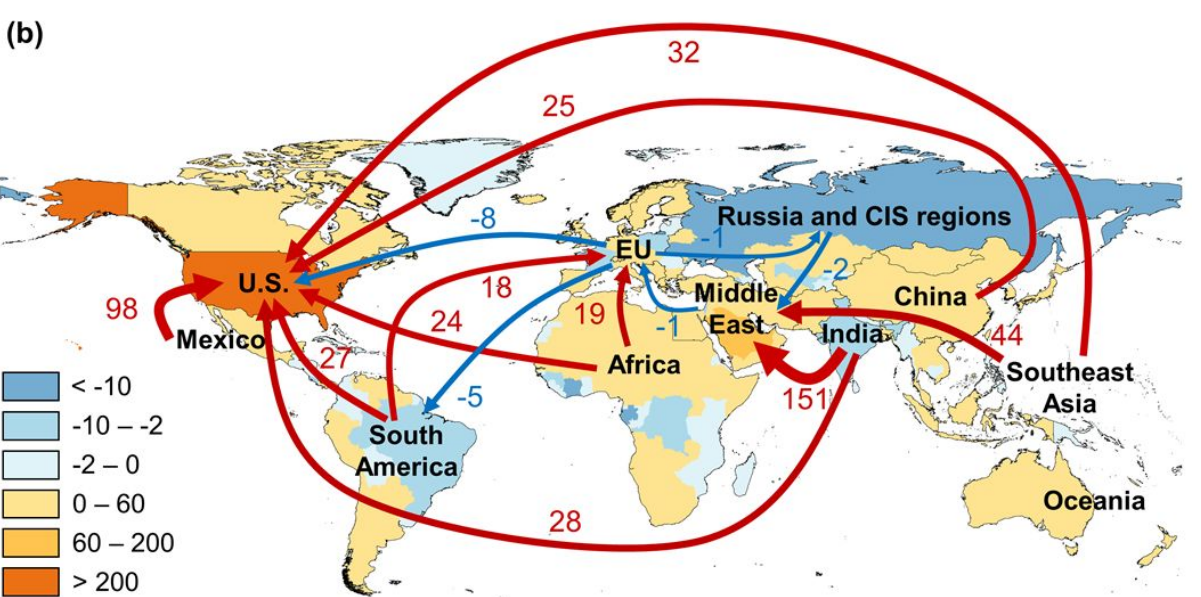

(d)

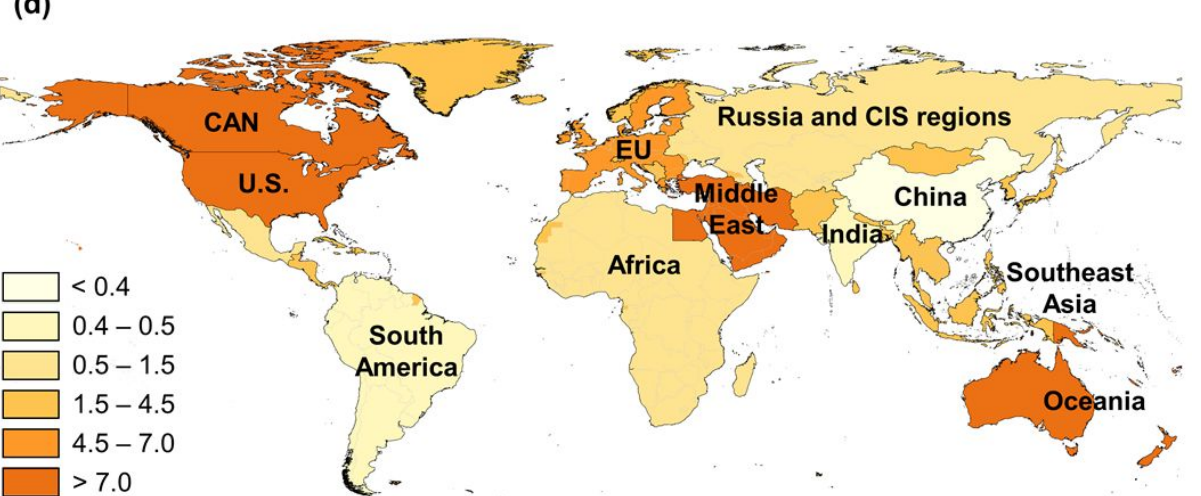

$>7.0$
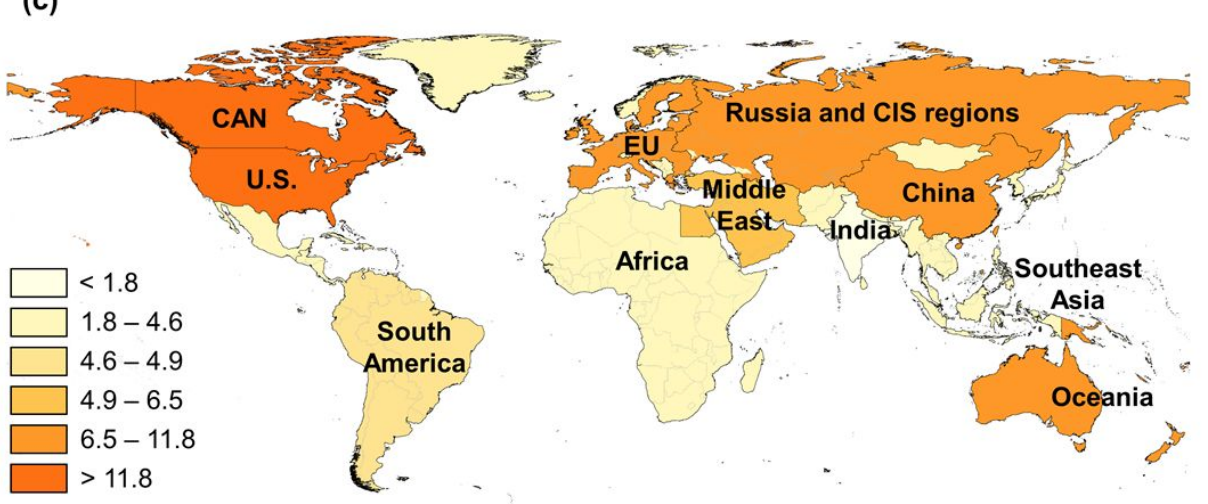
314 Figure 2. Global $\mathrm{immiCO}_{2}$ and $\mathrm{immiCO}_{2}$ flows. Panel (a) illustrates the global $\mathrm{immiCO}_{2}$ and the critical sub-regional flows in 2015 (Mt). Panel

315 (b) shows the changes in immiCO 2 and the critical sub-regional flows during 1995-2015 (Mt). The colour of nations in the world maps shows

316 their $\mathrm{immiCO}_{2}$ (a) and $\mathrm{immiCO}_{2}$ changes (b). The arrows start from the origins of immigrants and end at their destinations (at the sub-regional

317 scale). The numbers and width of the arrows indicate the $\mathrm{immiCO}_{2}$ (a) and the changes in immiCO $(\mathrm{b})$. The red arrows indicate an increased

$318 \mathrm{immiCO}_{2}$ caused by the migration flows, while the blue ones represent a decrease. Panel (c) illustrates the per capita immiCO $\mathrm{in}_{2}$ each sub-

319 region in 2015 (ton per capita), where the colour of the sub-regions in the world maps shows their per capita immiCO ${ }_{2}$. Panel (d) shows the

320 portion of $\mathrm{immiCO}_{2}$ in total $\mathrm{CO}_{2}$ footprint for each sub-region in 2015 , where the colour of the sub-regions in the world maps shows their

321 proportions of $\mathrm{immiCO}_{2}$ in total $\mathrm{CO}_{2}$ footprint. 
Impacts of International Migration on Global $\mathrm{CO}_{2}$ Emissions. We evaluate the

relative contribution of the international migration to global $\mathrm{CO}_{2}$ emissions, by

324 decomposing global $\mathrm{CO}_{2}$ emissions into six socioeconomic determinants (i.e., $\mathrm{CO}_{2}$

325 emission intensity, production structure, final demand structure, per capita final

326 demand, original population, and migration structure). Figure 3 reveals that global

$327 \mathrm{CO}_{2}$ emissions have increased steadily during 1995-2015, with the increasing per

328 capita final demand being the largest contributor. The reduction of $\mathrm{CO}_{2}$ emission

329 intensity has the most significant contribution to global $\mathrm{CO}_{2}$ mitigation. The changes

330 in the original population and international migrants structure have kept increasing

331 global $\mathrm{CO}_{2}$ emissions during 1995-2015. Natural population growth, which is the

332 second largest contributor to global $\mathrm{CO}_{2}$ emissions, contributes to an increase in

333 global $\mathrm{CO}_{2}$ emissions by over $4 \%$ every five years while changes in the international

334 migration structure act as the third largest contributor. The pushing effects of

335 migration structure changes vary across different time periods, with the highest being

$3360.7 \%$ during $2005-2010$ and the lowest being $0.1 \%$ during $2010-2015$. The impacts

337 of international migration structure changes on global $\mathrm{CO}_{2}$ emissions are expected to

338 be lower in recent years, because the migration structures of major migration

339 destinations have been plateaued. The changes in the final demand structure have

340 relatively small impacts on global $\mathrm{CO}_{2}$ emissions during 1995-2015. In general,

341 changes in the quantity, structure, and affluence of international immigrants have

342 contributed to global $\mathrm{CO}_{2}$ emissions increase during 1995-2015, while final demand 
343 structure changes of international immigrants have little effects on global $\mathrm{CO}_{2}$

344 emissions during this time period.

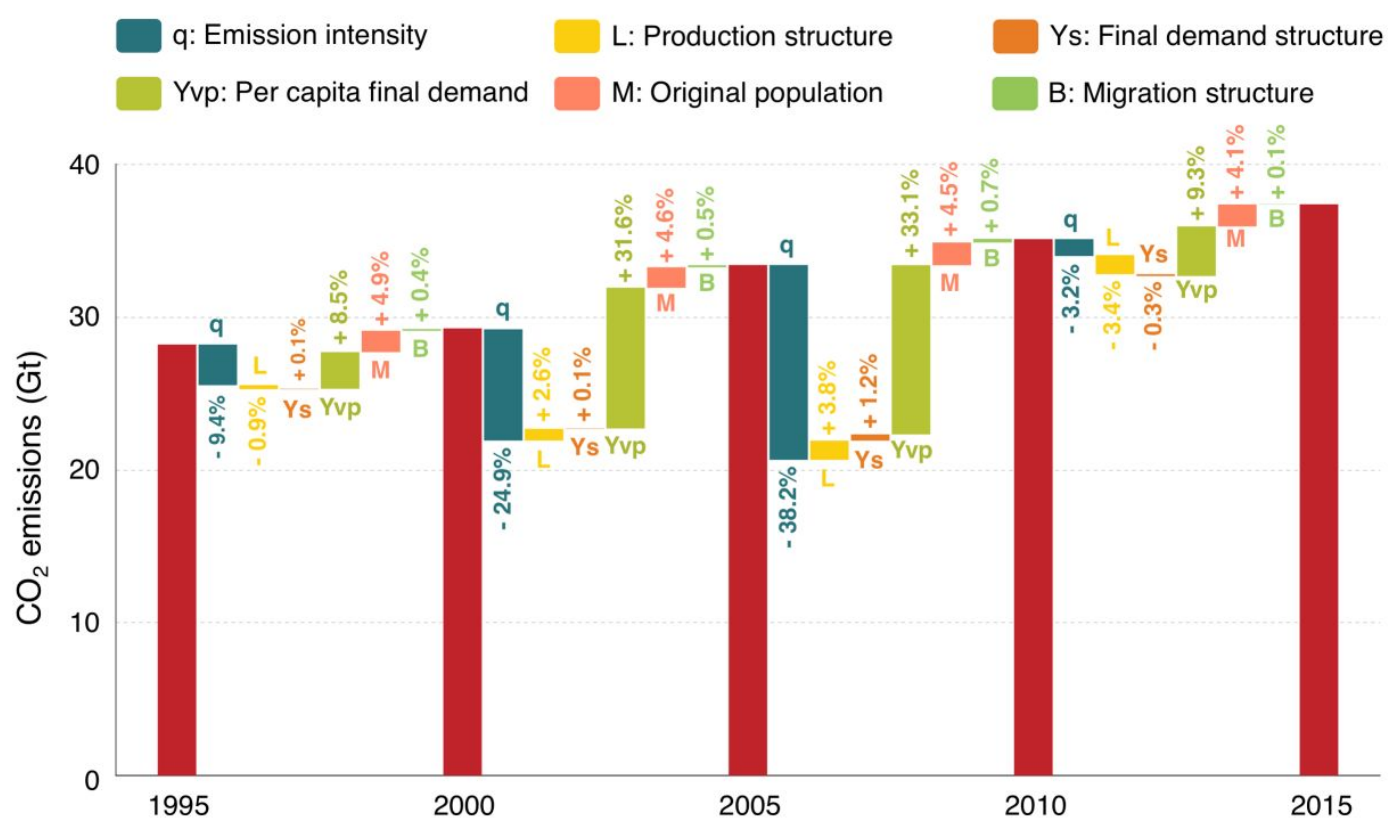

346 Figure 3. Impacts of socioeconomic transition and migration trend on changes in

347 global $\mathrm{CO}_{2}$ emissions during 1995-2015. The positive values indicate that

348 socioeconomic factor changes contribute to the increase of $\mathrm{CO}_{2}$ emissions, while the

349 negative values mean that the socioeconomic factor changes lead to the mitigation of $350 \mathrm{CO}_{2}$ emissions, if other factors remain constant.

\section{DISCUSSION}

353 This study for the first time examined the $\mathrm{CO}_{2}$ footprint of international immigrants.

354 The $\mathrm{CO}_{2}$ footprint of international immigrants has increased by $65 \%$ during $1995-$

355 2015, while that of the global population (i.e., global total $\mathrm{CO}_{2}$ emissions) has

356 increased by $33 \%$ during the same period. Meanwhile, the portion of the $\mathrm{CO}_{2}$ 
357 footprint of international immigrants in global total $\mathrm{CO}_{2}$ emissions has also increased.

358 International migrants accounted for $3.4 \%$ of the total population in 2015 , but its $\mathrm{CO}_{2}$

359 footprint was as high as $7.9 \%$. However, in 1995 the portion of international

360 immigrants and their $\mathrm{CO}_{2}$ footprint was only $2.8 \%$ and $6.3 \%$, respectively. Since

361 migration is generally from relatively poorer regions to richer regions, immigrants

362 would typically live in more advanced economies with significant lifestyle change.

363 Their consumption of living necessities (e.g., foods and clothes), housing,

364 infrastructures, health care, and education would be more $\mathrm{CO}_{2}$ intensified, and cause

365 more massive $\mathrm{CO}_{2}$ emissions. This finding facilitates policy makers to reconsider the

366 role and status of global population mobility in $\mathrm{CO}_{2}$ emissions. Population mobility

367 will accompany the development and transformation of human society for a long

368 time. The understanding of the $\mathrm{CO}_{2}$ footprint of human migration in this study will

369 contribute to current efforts and routes to tackle climate changes. At the same time,

370 this study reveals that migration structure tends to be stable in recent years, and the

371 changes in the number of immigrants are the main factor influencing migration-

372 related $\mathrm{CO}_{2}$ emissions.

373 Policy implication I: $\mathrm{CO}_{2}$ reduction targets of the Paris Agreement and

374 subsequent agreements must consider the effects of global migration. Many

375 nations have set their Nationally Determined Contributions (NDCs) since the Paris

376 Agreement in $2016^{42}$. However, $\mathrm{CO}_{2}$ emission changes caused by global population

377 movements have not been fully considered in current targets. The allocation of 
responsibilities for global $\mathrm{CO}_{2}$ emission reduction can be different when considering

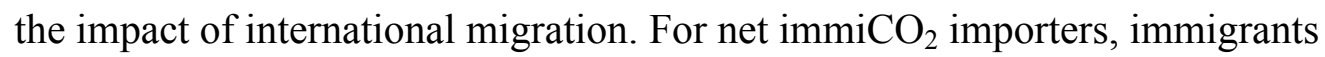
contribute to $\mathrm{CO}_{2}$ emissions in these nations, which increases the challenges of $\mathrm{CO}_{2}$ emission reduction. Based on our results, the U.S. is still a primary destination of global migrants. It is likely to maintain this trend for a long time to come. Thus, the pressure for $\mathrm{CO}_{2}$ emission reduction in the U.S. will be more severe in the future. The U.S., as the second largest $\mathrm{CO}_{2}$ emitter in the world, has withdrawn from the Paris Agreement. This situation will pose great challenges to global climate changes. major migration destinations. They need to consider future changes in the number and structure of population movements when setting their NDCs.

\section{Policy implication II: Both production-side and demand-side measures are} required to curb $\mathrm{CO}_{2}$ emissions caused by international migration.

391 On one hand, production-side measures are important to offset the impacts of

392 international migration on global $\mathrm{CO}_{2}$ emissions. For producers, decreasing their $\mathrm{CO}_{2}$

393 emission intensity is beneficial to lowering $\mathrm{CO}_{2}$ footprint of the whole supply chain.

394 Although international migration affects the consumption, the decreased $\mathrm{CO}_{2}$

395 emission intensity can offset the impact of consumption pattern changes on $\mathrm{CO}_{2}$

396 emissions to some extent. Since migration restriction is not a desirable option for

397 economic development, immigrant inflow nations should accelerate both the

398 reduction of $\mathrm{CO}_{2}$ emission intensity of their own economic systems and the transition 
399 to the post-fossil energy era. In this way, even if the migration pushes up the overall

400 population, it will not cause a significant increase in $\mathrm{CO}_{2}$ emissions.

401 Compared with the U.S., the overall $\mathrm{CO}_{2}$ footprint of immigrants in Europe

402 (especially in Nordic countries such as Denmark and Sweden) is much lower. Nordic

403 countries have made significant efforts to reduce $\mathrm{CO}_{2}$ emissions. Their own $\mathrm{CO}_{2}$

404 footprint is relatively low, despite immigrant inflows. Subsequently, there is no

405 significant promotion of their own $\mathrm{CO}_{2}$ emissions. This fully illustrates that reducing

406 the intensity of $\mathrm{CO}_{2}$ emissions in their economies can significantly reduce the

407 boosting effects of $\mathrm{CO}_{2}$ emissions brought by immigrants.

408 The individual $\mathrm{CO}_{2}$ footprint will have a downward trend, if immigrants move from

409 high $\mathrm{CO}_{2}$ emitting nations to low $\mathrm{CO}_{2}$ emitters. In some Middle East energy-

410 dependent nations, immigrants from India and other major nations can significantly

411 boost their $\mathrm{CO}_{2}$ emissions. How to accelerate the transition to a post-fossil energy era

412 in relevant nations will be a major challenge.

413 On the other hand, demand-side measures need to focus on major immigrant inflow

414 nations, and sustainable consumption strategies of major immigrant inflow nations

415 need to consider the trade-off effects of future migration. Major immigrant inflow

416 nations should fully consider $\mathrm{CO}_{2}$ boosting effects of future migration, especially in

417 nations with high $\mathrm{CO}_{2}$ emissions (e.g., the U.S. identified in this study). Since

418 international migration is inevitable in the context of globalization, it is crucial for

419 immigrant inflow nations to optimize consumption behaviors (e.g., guiding the 
420 consumption through carbon tax on finished goods and services) and accelerate

421 technology improvements. In particular, consumption behaviors of immigrants should

422 be guided through tax or financial incentives to decrease $\mathrm{immiCO}_{2}$. Moreover,

423 industries should be encouraged to choose upstream inputs with lower $\mathrm{CO}_{2}$ emission

424 intensities. In this way, the immigrant inflow nations may not suffer huge rises in $\mathrm{CO}_{2}$

425 emissions under the impact of international migration.

426 Limitations. This study focuses on the macro-scale analyses. We assume that the

427 consumption structure of immigrants is the same as that of native people in immigrant

428 destination. The ratio of immigrants to total population is used to analyze the impact

429 of international migration on global $\mathrm{CO}_{2}$ emissions. Other underlying factors

430 influencing $\mathrm{CO}_{2}$ emissions through international migration are not considered due to

431 data unavailability. These factors (e.g., lifestyles in different immigrant destinations,

432 destination selection of immigrants, and consumption custom of different ethnic

433 groups) can be further considered in future studies based on micro-level databases and

434 social surveys.

435 In this study, we only calculated the $\mathrm{CO}_{2}$ emission effects of global migration,

436 without considering other effects caused by the migration (e.g., economic and social

437 impacts). The primary cause of immigrants' $\mathrm{CO}_{2}$ emissions is also related to the high-

438 carbon economic systems of destination nations. The relevant policies should focus on

439 how to reduce the $\mathrm{CO}_{2}$ footprint of their own economic systems. Meanwhile, there is

440 also a trend of international migration to low-income or low-carbon nations. In the 
441 future, global migration will become more diversified, and thus the $\mathrm{CO}_{2}$ footprint of

442 immigrants will be more diversified.

443 Uncertainty. The MRIO tables and global $\mathrm{CO}_{2}$ emissions in this study are from the

444 Eora database ${ }^{37,38}$. Data of other global MRIO databases (e.g., GTAP ${ }^{43}$, WIOD $^{44}$,

445 EXIOBASE ${ }^{45-47}$ ) are not identical with that of Eora, which may lead to differences in

446 results. Moreover, the international migration data are based on the number of

447 documented immigrants. The undocumented immigrants, which also draw

448 international attention, are not considered in this study due to data unavailability.

449 These issues can be further addressed when the databases and statistical accuracy are 450 improved.

\section{ASSOCIATED CONTENT}

\section{Supporting Information}

454 The supporting information provides supplemental Figures and Data supporting the

455 main text. In the SI, Figure S1 for the international migration population and

456 migration change; and Figure $\mathrm{S} 2$ for the national immi $\mathrm{CO}_{2}$ and $\mathrm{immiCO}_{2}$ flows. In

457 the Supporting Data, Data S1 for the immigrant polulation and total polulation of

458 nations; Data $\mathrm{S} 2$ for the $\mathrm{immiCO}_{2}$ of nations; Data $\mathrm{S} 3$ for the proportions of $\mathrm{immiCO}_{2}$

459 in total $\mathrm{CO}_{2}$ footprint of nations; and Data $\mathrm{S} 4$ for the list of nations and associated

460 sub-regions. 


\section{AUTHOR INFORMATION}

463

464

465

466

467

468

\section{Corresponding Authors}

Yutao Wang - Fudan Tyndall Center and Shanghai Key Laboratory of Atmospheric Particle Pollution and Prevention (LAP3), Department of Environmental Science \& Engineering, Fudan University, Shanghai, 200438, China; Email: yutaowang@fudan.edu.cn

Dabo Guan - Department of Earth System Science, Tsinghua University, Beijing, 100080,China; Email: guandabo@hotmail.com

\section{Authors}

Sai Liang - Key Laboratory for City Cluster Environmental Safety and Green Development of the Ministry of Education, Institute of Environmental and Ecological Engineering, Guangdong University of Technology, Guangzhou, Guangdong, 510006, China; State Key Joint Laboratory of Environment Simulation and Pollution Control, School of Environment, Beijing Normal University, Beijing, 100875, China.

Xuechun Yang - State Key Joint Laboratory of Environment Simulation and Pollution Control, School of Environment, Beijing Normal University, Beijing, 100875, China. 

University, Beijing, 100875, China.

495 The authors declare no competing financial interests.

\section{Notes}


498 This work was financially supported by the National Natural Science Foundation of 499 China (71874014; 71774032; 71961137009) and Newton Advanced Fellowship from 500 the British Academy and the Newton Fund (NAFR2180103).

502 REFERENCES

503 (1) Young, Y.; Loebach, P.; Korinek, K. Building walls or opening borders? Global 504 immigration policy attitudes across economic, cultural and human security contexts.

505 Soc. Sci. Res. 2018, 75, 83-95.

506 (2) Duncan, N. T.; Waldorf, B. S. Immigrant selectivity, immigrant performance and 507 the macro-economic context. Reg. Sci. Pol. Prac. 2016, 8, (3), 127-143.

508 (3) Hatton, T. J.; Williamson, J. G. The impact of immigration: Comparing two 509 global eras. World. Dev. 2008, 36, (3), 345-361.

510 (4) De Sherbinin, A.; VanWey, L. K.; McSweeney, K.; Aggarwal, R.; Barbieri, A.;

511 Henry, S.; Hunter, L. M.; Twine, W.; Walker, R. Rural household demographics,

512 livelihoods and the environment. Global Environ. Chang. 2008, 18, (1), 38-53.

513 (5) Taylor, M. J.; Aguilar-Støen, M.; Castellanos, E.; Moran-Taylor, M. J.; Gerkin, 514 K. International migration, land use change and the environment in Ixcán, Guatemala. 515 Land Use Policy 2016, 54, 290-301. 
516 (6) Radel, C.; Schmook, B.; McCandless, S. Environment, transnational labor

517 migration, and gender: case studies from southern Yucatán, Mexico and Vermont,

518 USA. Popul. Environ. 2010, 32, (2), 177-197.

519 (7) Oldekop, J. A.; Sims, K. R. E.; Whittingham, M. J.; Agrawal, A. An upside to

520 globalization: International outmigration drives reforestation in Nepal. Global

521 Environ. Chang. 2018, 52, 66-74.

522 (8) Pan, W.; Carr, D.; Barbieri, A.; Bilsborrow, R.; Suchindran, C. Forest clearing in

523 the Ecuadorian Amazon: a study of patterns over space and time. Popul. Res. Policy.

524 Rev. 2007, 26, (5-6), 635-659.

525 (9) Li, G.; Fang, C.; Wang, S.; Sun, S. The effect of economic growth, urbanization,

526 and industrialization on fine particulate matter $\left(\mathrm{PM}_{2.5}\right)$ concentrations in China.

527 Environ. Sci. Technol. 2016, 50, (21), 11452-11459.

528 (10)Lin, B.; Zhu, J. Changes in urban air quality during urbanization in China. $J$.

529 Clean. Prod. 2018, 188, 312-321.

530 (11)Ponce de Leon Barido, D.; Marshall, J. D. Relationship between urbanization and

$531 \mathrm{CO}_{2}$ emissions depends on income level and policy. Environ. Sci. Technol. 2014, 48,

532 (7), 3632-3639.

533 (12)Bekhet, H. A.; Othman, N. S. Impact of urbanization growth on Malaysia $\mathrm{CO}_{2}$

534 emissions: Evidence from the dynamic relationship. J. Clean. Prod. 2017, 154, 374-

535388. 
536 (13)Qi, W.; Li, G. Residential carbon emission embedded in China's inter-provincial 537 population migration. Energ. Policy. 2020, 136, 111065.

538 (14)Feng, K.; Hubacek, K. Carbon implications of China's urbanization. Energ. Ecol. 539 Environ. 2016, 1, (1), 39-44.

540 (15)DinAlt, J. The environmental impact of immigration into the United States.

541 http://www.carryingcapacity.org/DinAlt.htm

542 (16)Cafaro, P.; Staples, W. The environmental argument for reducing immigration to 543 the United States. J. Soc. Polit. Econ. Stud. 2009, 34, (3), 290-317.

544 (17)Zhao, X.; Li, N.; Ma, C. Residential energy consumption in urban China: A

545 decomposition analysis. Energ. Policy. 2012, 41, (C), 644-653.

546 (18)Price, C.; Feldmeyer, B. The environmental impact of immigration: An analysis

547 of the effects of immigrant concentration on air pollution levels. Popul. Res. Policy.

548 Rev. 2012, 31, (1), 119-140.

549 (19)Squalli, J. An empirical assessment of U.S. state-level immigration and

550 environmental emissions. Ecol. Econ. 2010, 69, (5), 1170-1175.

551 (20)Ma, G.; Hofmann, E. T. Population, immigration, and air quality in the USA: a

552 spatial panel study. Popul. Environ. 2019, 40, (3), 283.

553 (21)Lenzen, M.; Sun, Y.-Y.; Faturay, F.; Ting, Y.-P.; Geschke, A.; Malik, A. The

554 carbon footprint of global tourism. Nat. Clim. Change 2018, 8, (6), 522-528. 
555 (22)Teixeira, C. Living on the "edge of the suburbs" of Vancouver: A case study of

556 the housing experiences and coping strategies of recent immigrants in Surrey and

557 Richmond. Can, Geogr 2014, 58, (2), 168-187.

558 (23)Larrotta, C. Immigrants to the United States and adult education services. New

559 Directions for Adult and Continuing Education 2017, 2017, (155), 61-69.

560 (24)Liebert, S.; Ameringer, C. F. The health care safety net and the affordable care

561 act: Implications for hispanic immigrants. Public Admin. Rev. 2013, 73, (6), 810-820.

562 (25)United Nations Department of Economic and Social Affairs International

563 migration stock: The 2017 revision.

564 https://www.un.org/en/development/desa/population/migration/data/estimates2017/est

565 imates17.asp

566 (26)World Bank Population, total.

567 https://data.worldbank.org/indicator/SP.POP.TOTL

568 (27)Peters, G. P. From production-based to consumption-based national emission

569 inventories. Ecol. Econ. 2008, 65, (1), 13-23.

570 (28)Mi, Z.; Meng, J.; Guan, D.; Shan, Y.; Song, M.; Wei, Y.-M.; Liu, Z.; Hubacek,

571 K. Chinese $\mathrm{CO}_{2}$ emission flows have reversed since the global financial crisis. Nat.

572 Commun. 2017, 8, (1), No.1712.

573 (29)Liang, S.; Qu, S.; Zhu, Z.; Guan, D.; Xu, M. Income-based greenhouse gas

574 emissions of nations. Environ. Sci. Technol. 2017, 51, (1), 346-355. 
575 (30)Liang, S.; Wang, Y.; Cinnirella, S.; Pirrone, N. Atmospheric mercury footprints 576 of nations. Environ. Sci. Technol. 2015, 49, (6), 3566-3574.

577 (31)Qi, J.; Wang, Y.; Liang, S.; Li, Y.; Li, Y.; Feng, C.; Xu, L.; Wang, S.; Chen, L.; 578 Wang, D.; Yang, Z. Primary suppliers driving atmospheric mercury emissions 579 through global supply chains. One Earth 2019, 1, (2), 254-266.

580 (32)Wiedmann, T. O.; Schandl, H.; Lenzen, M.; Moran, D.; Suh, S.; West, J.;

581 Kanemoto, K. The material footprint of nations. Proc. Natl. Acad. Sci. U S A 2015, $582 \quad 112,(20), 6271-6276$.

583 (33)Font Vivanco, D.; Sprecher, B.; Hertwich, E. Scarcity-weighted global land and 584 metal footprints. Ecol. Indic. 2017, 83, 323-327.

585 (34)Wang, H.; Wang, G.; Qi, J.; Schandl, H.; Li, Y.; Feng, C.; Yang, X.; Wang, Y.;

586 Wang, X.; Liang, S. Scarcity-weighted fossil fuel footprint of China at the provincial 587 level. Appl. Energ. 2020, 258, 114081.

588 (35)Zhang, Q.; Jiang, X.; Tong, D.; Davis, S. J.; Zhao, H.; Geng, G.; Feng, T.; Zheng, 589 B.; Lu, Z.; Streets, D. G.; Ni, R.; Brauer, M.; van Donkelaar, A.; Martin, R. V.; Huo, 590 H.; Liu, Z.; Pan, D.; Kan, H.; Yan, Y.; Lin, J.; He, K.; Guan, D. Transboundary health 591 impacts of transported global air pollution and international trade. Nature 2017, 543, 592 (7647), 705-709.

593 (36)Chen, L.; Liang, S.; Liu, M.; Yi, Y.; Mi, Z.; Zhang, Y.; Li, Y.; Qi, J.; Meng, J.;

594 Tang, X.; Zhang, H.; Tong, Y.; Zhang, W.; Wang, X.; Shu, J.; Yang, Z. Trans- 
595 provincial health impacts of atmospheric mercury emissions in China. Nat. Commun. $5962019,10,(1), 1484$.

597 (37)Lenzen, M.; Kanemoto, K.; Moran, D.; Geschke, A. Mapping the structure of the 598 world economy. Environ. Sci. Technol. 2012, 46, (15), 8374-8381.

599 (38)Lenzen, M.; Moran, D.; Kanemoto, K.; Geschke, A. Building EORA: A global 600 multi-region input-output database at high country and sector resolution. Econ. Syst. 601 Res. 2013, 25, (1), 20-49.

602 (39)Lan, J.; Malik, A.; Lenzen, M.; McBain, D.; Kanemoto, K. A structural 603 decomposition analysis of global energy footprints. Appl. Energ. 2016, 163, 436-451. 604 (40)Malik, A.; Lan, J.; Lenzen, M. Trends in global greenhouse gas emissions from 6051990 to 2010. Environ. Sci. Technol. 2016, 50, (9), 4722-4730.

606 (41)United States Bureau of Labor Statistics Producer Price Indexes (PPI).

607 https://www.bls.gov/ppi/

608 (42)United Nations Framework Convention on Climate Change (UNFCCC)

609 Nationally Determined Contributions (NDCs). https://unfccc.int/process-and-

610 meetings/the-paris-agreement/nationally-determined-contributions-ndcs

611 (43)Aguiar, A.; Chepeliev, M.; Corong, E.; McDougall, R.; van der Mensbrugghe, D. 612 The GTAP Data Base: Version 10. Journal of Global Economic Analysis 2019, 4, (1), $613 \quad 1-27$. 
614 (44)Timmer, M. P.; Dietzenbacher, E.; Los, B.; Stehrer, R.; Vries, G. J. An Illustrated 615 User Guide to the World Input-Output Database: the Case of Global Automotive 616 Production. Rev. Int. Econ. 2015, 23, (3), 575-605.

617 (45)Tukker, A.; de Koning, A.; Wood, R.; Hawkins, T.; Lutter, S.; Acosta, J.; Rueda

618 Cantuche, J. M.; Bouwmeester, M.; Oosterhaven, J.; Drosdowski, T.; Kuenen, J.

619 EXIOPOL - Development and illustrative analyses of a detailed global MR EE

620 SUT/IOT. Economic Systems Research: Global Multiregional Input-Output

621 Frameworks 2013, 25, (1), 50-70.

622 (46)Stadler, K.; Wood, R.; Bulavskaya, T.; Södersten, C. J.; Simas, M.; Schmidt, S.;

623 Usubiaga, A.; Acosta-Fernández, J.; Kuenen, J.; Bruckner, M.; Giljum, S.; Lutter, S.;

624 Merciai, S.; Schmidt, J. H.; Theurl, M. C.; Plutzar, C.; Kastner, T.; Eisenmenger, N.;

625 Erb, K. H.; Koning, A.; Tukker, A. EXIOBASE 3: Developing a Time Series of

626 Detailed Environmentally Extended Multi-Regional Input-Output Tables. J. Ind. Ecol.

627 2018, 22, (3), 502-515.

628 (47)Merciai, S.; Schmidt, J. Methodology for the Construction of Global Multi-

629 Regional Hybrid Supply and Use Tables for the EXIOBASE v3 Database. J. Ind.

630 Ecol. 2018, 22, (3), 516-531. 


\section{For Table of Contents Only}

636

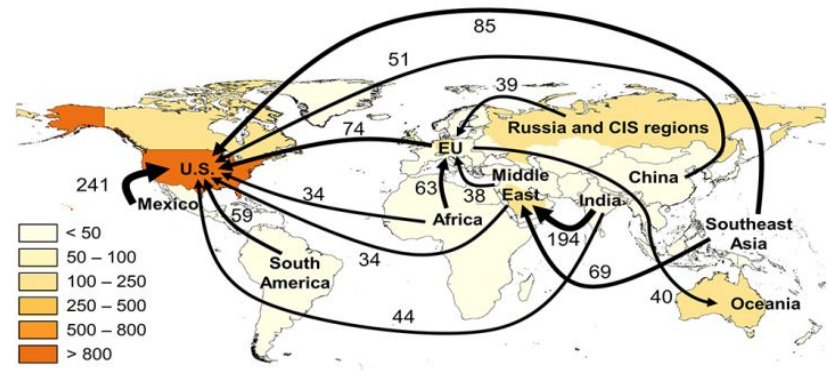

